\title{
Deposition of Multicomponent Alloys on Low-Carbon Steel Using Gas Tungsten Arc Welding (GTAW) Cladding Process
}

\author{
Jie H. Chen ${ }^{1}$, Pei N. Chen ${ }^{1}$, Pei H. Hua ${ }^{1}$, Ming C. Chen ${ }^{1}$, Yin Y. Chang ${ }^{2}$ and Weite Wu ${ }^{1, *}$ \\ ${ }^{1}$ Department of Materials Science and Engineering, National Chung Hsing University, Taichung 402, Taiwan, R.O.China \\ ${ }^{2}$ Department of Materials Science and Engineering, MingDao University, Chunghua 52345, Taiwan, R.O.China
}

\begin{abstract}
In this study, multicomponent alloy fillers were deposited on low-carbon steel substrates using gas tungsten arc welding (GTAW) process. The microstructure and wear properties of Al-Co-Cr-Ni-Mo-Fe-Si multicomponent alloys were studied. The GTAW cladding layers were analyzed by X-ray diffraction (XRD), field-emission scanning electron microscopy (FE-SEM), X-ray energy dispersive spectroscopy (EDS), and transmission electron microscope (TEM). The results show that the microstructure mainly consisted of dendritic FeMoSi and interdendritic BCC phases and that the addition of Si coarsened the primary FeMoSi phase. In addition, different precipitate morphologies were found in the interdendrites. As the Si content increased from 5.92 to 14.53 at $\%$, the microhardness also increased from 826 to $885 \mathrm{Hv}$ and the wear resistance improved significantly. The FeMoSi dendrites possessed covalent-dominant strong atomic bonds that enhanced the hardness and wear resistance of claddings. [doi:10.2320/matertrans.MRP2008276]
\end{abstract}

(Received August 18, 2008; Accepted January 6, 2009; Published February 25, 2009)

Keywords: microstructure, cladding process, wear, multicomponent alloys

\section{Introduction}

Some industrial applications require components with special surface properties such as hardness, wear resistance, and corrosion resistance. The most effective and economical material-processing method produces a surface metallic cladding with many advantages: (1) the fusion bonding of the material with the substrate is good, (2) it is easy to use, and (3) it consists of a workpiece that has improved surface properties. ${ }^{1-3)}$ Surface cladding methods using a high energy density source such as an electric arc and laser have been widely applied commercially to enhance surface properties of materials. Laser cladding, flame spraying, gas tungsten arc welding (GTAW) cladding, and plasma spraying are among the widely used surface cladding processes that can produce relatively thick cladding layers. ${ }^{2-6)}$ Among these processes, GTAW cladding is one of the most promising processes because of its high deposition rate and wide applicability. ${ }^{6-9)}$

This process uses a nonconsumable tungsten electrode and an inert gas for arc shielding. An electric arc is established between the tungsten electrode and the part to be welded. The GTAW process associated with rapid heating and cooling rates can be used for the nonequilibrium synthesis of materials and for the rapid production of solidified fine microstructures that have an extended solid solution for alloying elements. This surface cladding method can be used to reinforce local surfaces in various wear and corrosion resistance applications.

Cladding materials such as Fe-, Ni-, and Co-based alloys in addition to carbides and borides are commercially available and widely used. Ni- and Co-based alloys are used in hightemperature applications and they provide the best overall combination of high corrosion (or heat resistance) and wear resistance. ${ }^{10-12)}$ Theories on the occurrence, structure, and properties of the crystalline phases of current commercial and industrial alloys are limited to alloys based on one or two main components.

*Corresponding author, E-mail: d9466112@mail.nchu.edu.tw
In recent years, alloys containing several main components in approximately equal proportions have been investigated by Cantor et al. ${ }^{13)}$ Multicomponent alloys in equimolar or near equimolar ratios have been developed by Yeh et al. ${ }^{14-18)}$ The alloys in these studies have many excellent mechanical and chemical properties such as high hardness, high mechanical strength, and high wear and corrosion resistance. ${ }^{13-19)}$ The application of multicomponent alloys in equimolar ratios in surface cladding should be examined. Accordingly, in the present study, a surface of composite cladding reinforced by a multicomponent alloy filler on low-carbon steel was prepared. A GTAW heat source was used for this task under a nonoxidizing atmosphere protected by argon gas flow. The effects of various Si contents on the surface cladding were then compared and investigated systematically.

\section{Experimental Procedure}

Specimens with low-carbon steel as the base metal were fabricated into $100 \times 40 \times 10 \mathrm{~mm}$ rectangular plates. The chemical composition of low-carbon steel is as follows: $\mathrm{C}$, $0.15 \%$; $\mathrm{Mn}, 0.32 \%$; P, 0.04\%; $\mathrm{Si}, 0.27 \%$; and $\mathrm{Fe}$, balance. The base metal surface was ground and cleaned with acetone before the cladding process was performed. Surface claddings were arc melted in an argon atmosphere using a watercooled copper crucible and a nonconsumable tungsten electrode.

Multicomponent alloy fillers $(60 \times 25 \times 3 \mathrm{~mm})$ were prepared by mixing an equimolar ratio of $\mathrm{Ni}, \mathrm{Co}, \mathrm{Cr}, \mathrm{Al}$, and Mo with various amounts of Si $(5,10$, and 15 at $\%)$ in a mechanical mixer at a constant high pressure. It should be noted that the filler components did not include Fe. The Fe element was designed from a substrate material during cladding. Figure 1(a) shows the diagram of the GTAW process with oscillation and a pre-fixed alloy filler. Figure 1(b) shows the analytic position that was used for the microstructure observation, hardness test, and wear test. Table 1 lists the processing conditions. After the GTAW process, the cladding plates were sectioned for analyzing the 


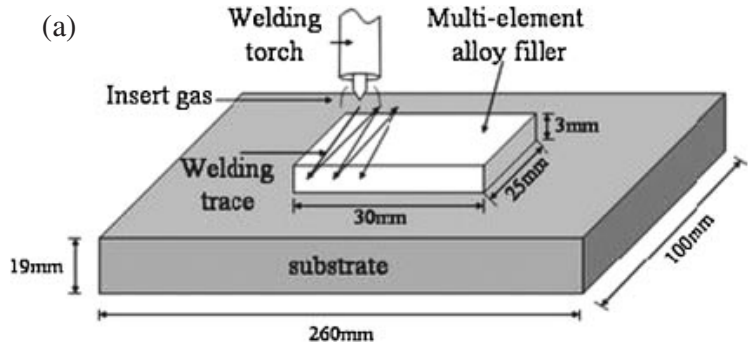

(b)

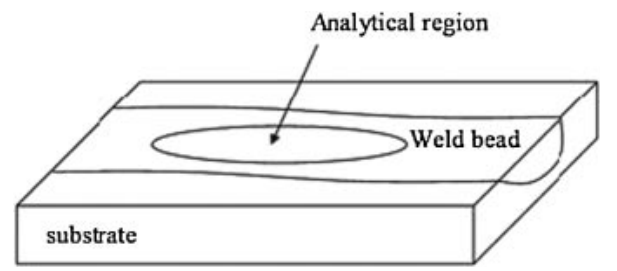

Fig. 1 Diagram of GTAW process.

Table 1 Parameters of GTAW cladding process.

\begin{tabular}{lc}
\hline \multicolumn{1}{c}{ Parameter } & Conditions \\
\hline Protective gas & $\mathrm{Ar}$ \\
Gas flow & $15(1 / \mathrm{min})$ \\
Electrode type & $\mathrm{W}-2 \% \mathrm{ThO}$ \\
Electrode diameter & $3.2(\mathrm{~mm})$ \\
Voltage & $15(\mathrm{~V})$ \\
Current & $220(\mathrm{~A})$ \\
Travel speed & $30(\mathrm{~mm} / \mathrm{min})$ \\
Oscillation speed & $300(\mathrm{~mm} / \mathrm{min})$ \\
\hline
\end{tabular}

cladding composition and performing metallographic observation and wear test sampling. Metallographic samples were ground using emery papers and polished with $\mathrm{Al}_{2} \mathrm{O}_{3}$ powder. The polished sample was etched with aqua regia. The microstructure of the cladding layer was analyzed by optical microscopy (OM) and field-emission scanning electron microscopy (FE-SEM). The chemical composition of the claddings was analyzed using energy dispersive spectroscopy (EDS). X-ray diffraction (XRD) analysis was used to identify the crystalline structure, with $2 \theta$ ranging from $20^{\circ}$ to $100^{\circ}$. Thin-foil specimens were prepared by mechanical thinning followed by ion milling, and observed using a FEI Tecnai $\mathrm{G}^{2}$ 20 S-Twin transmission electron microscope (TEM). The mean microhardness of the cladding layers was determined as the average of 10 measurements performed on the surface with a load of $9.8 \mathrm{~N}$. The cladding layers were tested for abrasive wear. The specimens were cleaned with acetone and then weighed by using an electronic balance with an accuracy of $\pm 0.1 \mathrm{mg}$. An abrasive wear test was conducted for a load of $130 \mathrm{~N}$, a sand-flow rate of $350 \mathrm{~g} / \mathrm{min}$, a wheel rotation rate of $200 \mathrm{rpm}$, and a total of 6000 wheel revolutions. The test followed the ASTM G65 dry sand/rubber wheel abrasion testing standard.

\section{Results and Discussion}

As a consequence of the GTAW cladding process, the prefixed mixed metallic powder fillers are melted on the

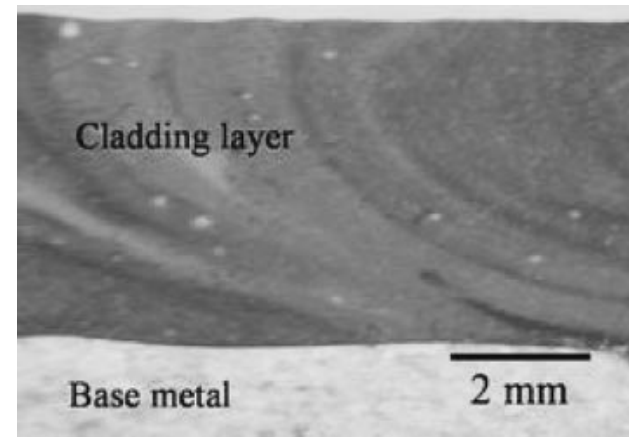

Fig. 2 OM image of the overall cross section of the GTAW-clad multicomponent alloy coating.

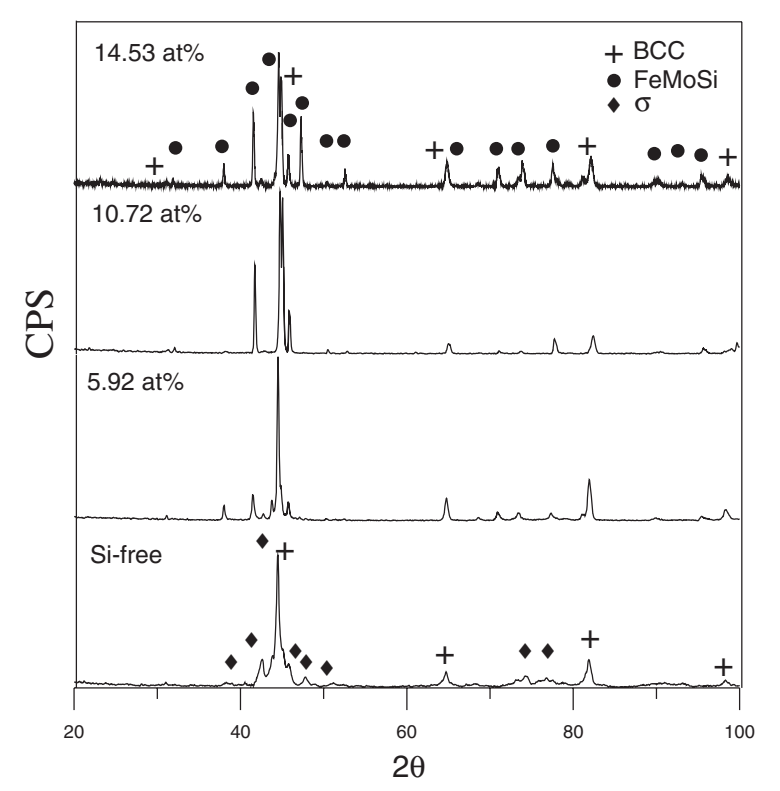

Fig. 3 XRD results of multicomponent alloy cladding for various $\mathrm{Si}$ contents.

substrate surface and then rapidly solidified to form a dense cladding bonded to the substrate. Figure 2 shows the morphology of the cladding layer. The thickness of the cladding layer was around $4 \mathrm{~mm}$. During the cladding process, the melt-pool diluted because of the melting of the substrate, and Fe was mixed into the melt-pool. The XRD patterns of the cladding layers are shown in Fig. 3. The Sifree specimen, whose microstructure is presented in the figures, consisted of a $\mathrm{BCC}$ phase and a $\sigma$ phase $(\mathrm{NiCoCr}-$ type). After the addition of $\mathrm{Si}$, a $\mathrm{BCC}$ and a FeMoSi diffraction pattern were observed within the XRD resolution. According to calculations based on Bragg's law, the lattice constant of the BCC phase was found to be $0.286 \mathrm{~nm}$ and the FeMoSi phase was found to be an HCP structure with $\mathrm{a}=0.765 \mathrm{~nm}$ and $\mathrm{c}=0.477 \mathrm{~nm}$. However, an order peak of the BCC phase was detected at $2 \theta=31^{\circ}$.

In our previous study, ${ }^{20)}$ the use of a $\mathrm{Si}$-free cladding layer resulted in the formation of a BCC solid solution and a $\sigma$ phase. The diffraction patterns of the $\sigma$ phase disappeared and the FeMoSi phase appeared upon the addition of Si. Thus, the addition of $\mathrm{Si}$ resulted in the formation of the FeMoSi phase in claddings. 
Table 2 Chemical compositions of cladding layers (at\%).

\begin{tabular}{llrcccccc}
\hline & $\mathrm{Si}$ & $\mathrm{Al}$ & $\mathrm{Cr}$ & $\mathrm{Fe}$ & $\mathrm{Co}$ & $\mathrm{Ni}$ & $\mathrm{Mo}$ \\
\hline \multirow{3}{*}{$5 \mathrm{Si}$} & Total & 5.92 & 8.7 & 15.61 & 27.36 & 13.54 & 11.75 & 17.12 \\
& Dendrite (D) & 5.89 & 3.39 & 13.37 & 25.02 & 14.41 & 7.00 & 18.75 \\
& Interdendrite (I) & 3.94 & 11.73 & 15.75 & 28.78 & 14.71 & 13.71 & 11.38 \\
& Total & 10.72 & 6.43 & 15.81 & 22.23 & 13.81 & 12.06 & 19.03 \\
$10 \mathrm{Si}$ & Dendrite (D) & 13.08 & 7.87 & 12.51 & 20.56 & 12.67 & 7.09 & 32.22 \\
& Interdendrite (I) & 8.62 & 9.84 & 13.3 & 24.17 & 14.18 & 14.26 & 15.94 \\
& Total & 14.53 & 8.9 & 12.51 & 28.15 & 11.49 & 11.32 & 13.1 \\
$15 \mathrm{Si}$ & Dendrite (D) & 15.88 & 2.61 & 10.81 & 26.07 & 9.98 & 6.21 & 28.45 \\
& Interdendrite (I) & 7.06 & 14.98 & 12.13 & 29.66 & 14.02 & 15.39 & 6.75
\end{tabular}

The microstructure of the cladding layers as observed under an optical microscope is shown in Figs. 4(a)-(d) and the chemical composition of integral regions is shown in Table 2. The Si-free cladding has a uniform fine strip-like microstructure. After the addition of $\mathrm{Si}$, a typical dendrite/ interdendrite microstructure consisting of cell primary dendrites with an $\mathrm{Si}$ content of 10.72 and 14.53 at\% was obtained. In addition, the distribution of cell dendrites in $14.53 \mathrm{at} \% \mathrm{Si}$ was coarser and denser than that of cell dendrites in 10.72 at\% Si. EDS was used to determine the composition of dendrite (labeled D in Fig. 5) and interdendrite (labeled I in Fig. 5) microstructures. The EDS analysis results were different from the designed composition. In the designed cladding compositions, Si was varied from 5 to 15 at $\%$ and the other elements had equiatomic percent ratios ranging from 15.83 to 14.1 at $\%$. However, the actual compositions of integral regions after cladding were observed to indicate low $\mathrm{Al}$ and high $\mathrm{Fe}$ concentrations. The reduction in the amount of $\mathrm{Al}$ can be attributed to its high chemical activity. The mixed metallic powders (filler) were arc melted into a welding pool during the GTAW process. A portion of the $\mathrm{Al}$ powder was heated and burned to reduce the $\mathrm{Al}$ content of the claddings by half. Thus, the actual composition of cladding layers can be expressed as $\mathrm{Al}_{0.5}-\mathrm{Co}-\mathrm{Ni}-\mathrm{Mo}-\mathrm{Fe}_{2}-\mathrm{Si}_{x}$.

The compositions of the dendrite and interdendrites of three claddings were compared. Dendrites contained a high proportion of $\mathrm{Fe}$ and Mo and were relatively rich in $\mathrm{Si}$, while interdendrites seemed to be relatively rich in $\mathrm{Ni}$ and $\mathrm{Al}$. The microstructure of the cladding layers as observed under an optical microscope is shown in Figs. 4(a)-(d). The Si-free cladding has a uniform fine strip-like microstructure. After the addition of $\mathrm{Si}$, a typical dendrite/interdendrite microstructure consisting of cell primary dendrites with an $\mathrm{Si}$ content of 10.72 and 14.53 at $\%$ was obtained. In addition, the distribution of cell dendrites in 14.53 at $\%$ Si was coarser and denser than that of cell dendrites in 10.72 at $\% \mathrm{Si}$.

The detailed microstructure of the cladding layers is shown in Figs. 5(a)-(d). With regard to the solidification of the microstructures, the Si-free multicomponent cladding (Fig. 5(a)) has a rapidly solidified uniform microstructure primarily consisting of the interconnecting strip-like and irregular block phase. The compositions (at\%) of the cladding layer were analyzed by EDS, and the following values were obtained: $\mathrm{Al}, 14.10 \%$; $\mathrm{Cr}, 16.63 \%$; $\mathrm{Fe}, 15.28 \%$; Co, $16.48 \%$; Ni, $18.8 \%$; and Mo, $18.8 \%$. It should be noted that the normal compositions of the cladding layer were
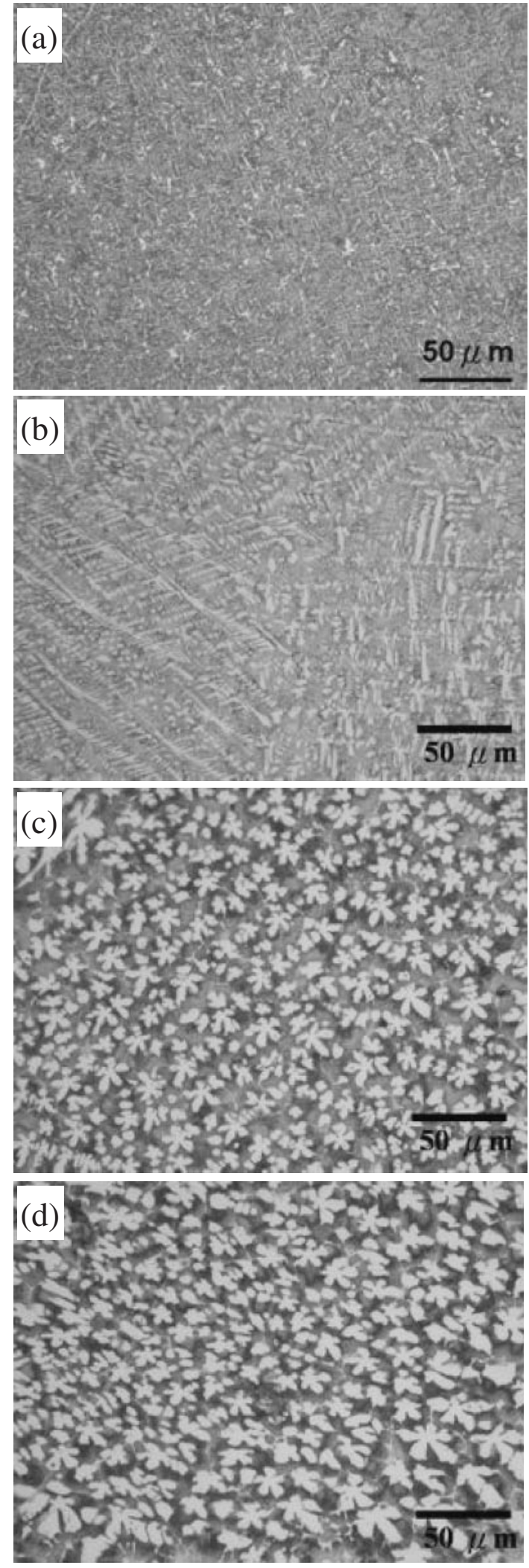

Fig. 4 OM image of cladding layers: (a) Si-free (b) 5.92 at\% Si, (c) 10.72 at $\% \mathrm{Si}$, (d) 14.53 at $\% \mathrm{Si}$.

similar to those of the equimolar multicomponent alloy system. The Fe-rich irregular block BCC phase and Mo-rich strip-like phase have been discussed in the previous study. ${ }^{20)}$ For a $\mathrm{Si}$ content of 5.92 at\%, the microstructure of the cladding layer shows a primary dendrite and a net-like 

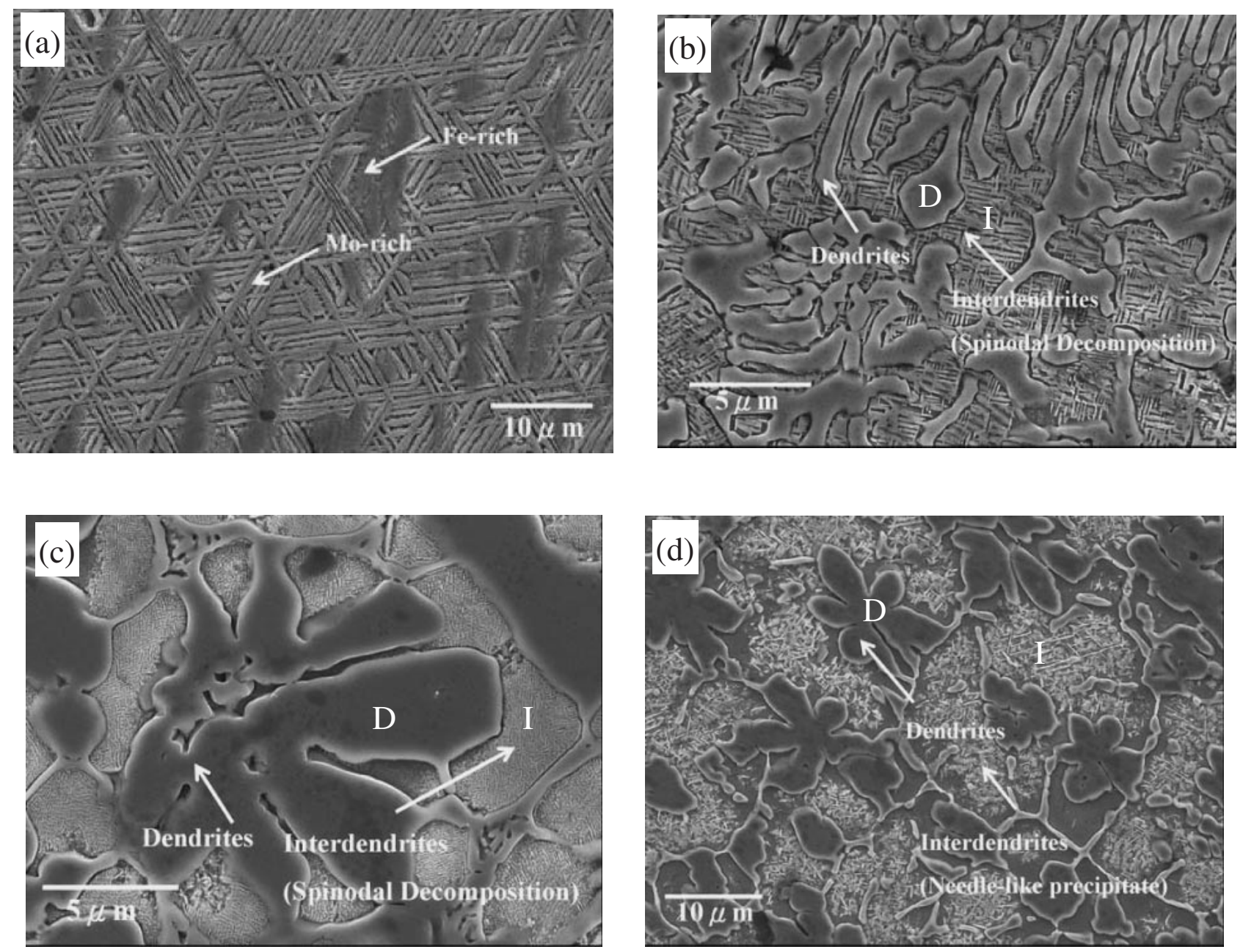

Fig. 5 SEM micrograph images for various Si contents: (a) Si-free (b) 5.92 at $\% \mathrm{Si}$, (c) 10.72 at\% $\mathrm{Si}$, (d) 14.53 at $\% \mathrm{Si}$.

structure of interdendrites. The net-like structure is believed to form through spinodal decomposition, and a similar structure has been reported in some previous studies. ${ }^{21,22)}$ For a Si content of 10.72 at $\%$, an initial region of the planar front growth occurs followed by the formation of a cell dendrite structure. The interdendrite presented a typical spinodal decomposition structure, which generally appears like a netlike structure. For a Si content of 14.53 at\%, the cell dendrites with a coarser and denser primary arm are observed. The morphology of the interdendrite regions is different from that of the other two claddings. For a Si content of 14.53 at $\%$, the interdendrite changes from spinodal decomposition structure to a needle-like precipitate.

According to XRD and EDS analyses, the dendrite rich in $\mathrm{Mo}, \mathrm{Fe}$, and Si consists of a FeMoSi phase with a multicomponent, and the interdendrite consists of a BCC phase. It is reasonable to believe the interdendrite consists of a $\mathrm{BCC}$ solid solution phase because it is rich in $\mathrm{Al}$ and $\mathrm{Al}$ is a stronger BCC phase former in muticomponent alloy systems. ${ }^{23-25)}$ Figure 6(a)-(b) presents a detailed analysis by TEM of the Si-free and of 14.53 at\% $\mathrm{Si}$ interdendrite. In Fig. 6(a), the microstructure is characterized in two regions which the iron-rich phase labeled A and the molybdenumrich phase labeled $\mathrm{B}$. The SAD patterns show the molybdenum-rich phase and the iron-rich phase consisting of tetragonal (zone axis [113]) and BCC phases (zone axis [001]). It is to be noted that the nanoscale crystalline structure is observed around region A (arrow area). In Fig. 6(b), some needle-like precipitates ( $100 \mathrm{~nm}$ in width and $1 \mu \mathrm{m}$ in length) can be observed. By comparing the TEM and SAD results, the long precipitates are verified to be disordered BCC Widmanstattenin-like precipitates that spread in an ordered BCC matrix. The (100) superlattice spot of the SAD pattern is shown in Fig. 6(b). In general, the nanoscale precipitate structure contributes to the precipitation and strength of the nanocomposites in alloy systems. ${ }^{26)}$ It is interesting to note that nanoscale precipitations are observed in many multicomponent alloy systems. ${ }^{21-23,25)}$ In general, the diffusional transformations occur as a result of thermally activated atomic movements; thus, the transformations involve the formation of phases with different components. Therefore, long-range diffusion is required. Based on this reasoning, diffusion of multiple elements in multicomponent alloy systems is relatively low, and this leads to the formation of nanoscale precipitates.

The hardness measurements performed for the cladding with different $\mathrm{Si}$ contents are shown in Fig. 7. It is evident that the maximum hardness values were obtained for the cladding surface with 14.53 at\% Si. The microhardness values of the dendrites and interdendrites of each specimen 

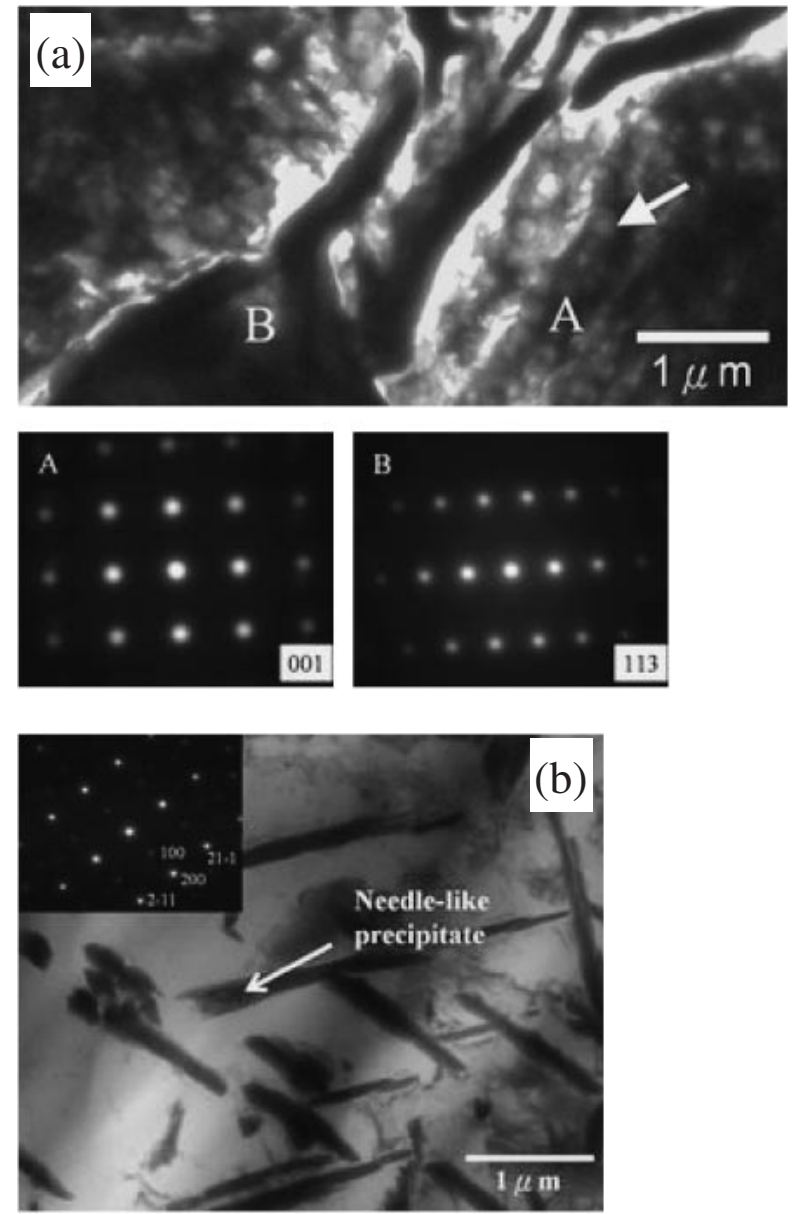

Fig. 6 TEM bright field image of (a) Si-free cladding layers displaying a microstructure consisting of irregular blocks with nanoscale crystalline (labeled A) and strip-like phases. (labeled B) SAD patterns consisting of body-center cubic to A (zone axis [001]) and tetragonal phase to B (zone axis [113]). (b) 14.53 at\% Si content cladding under bright field with SAD pattern of bcc [011] zone axis.

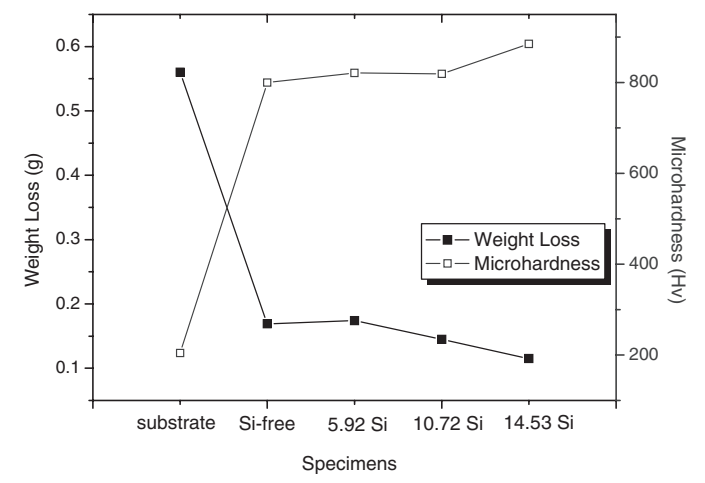

Fig. 7 Relation between hardness and wear mass loss for the GTAW cladding layer.

are listed in Table 3. The microhardness values of the primary dendrites and interdendrites were in the ranges of 856-900 HV and 768-812 HV, respectively. This increase in the hardness of 14.53 at\% $\mathrm{Si}$ is associated with the coarser and denser FeMoSi phase that possesses high Si content as compared to the other claddings.

In comparison with the un-cladding substrate, the multicomponent alloy cladding with a different $\mathrm{Si}$ content exhibits
Table 3 Microhardness of dendrites and interdendrites for various $\mathrm{Si}$ contents.

\begin{tabular}{ccc}
\hline Sample & Dendrites, & Interdendrites, \\
& Hv & 768 \\
\hline 5 at\% Si & 868 & 766 \\
10 at\% Si & 856 & 812 \\
15 at\% Si & 895 & \\
\hline
\end{tabular}

excellent wear resistance under dry sand/rubber wheel test conditions; this result is also shown in Fig. 7. It is observed that the Si-free and low $\mathrm{Si}$ content (5.89 at\%) claddings showed similar wear mass loss. Afterward, the weight loss decreases with an increase in the Si content. As the Si content increases to $14.53 \mathrm{at} \%$, the wear mass loss is $0.115 \mathrm{~g}$ and the wear resistance becomes as much as five times that of the substrate $(0.56 \mathrm{~g})$. The $\mathrm{Si}$ content has a remarkable influence on the wear resistance of the multicomponent alloy cladding. In general, the wear resistance of a material depends on its hardness. Thus, the excellent wear resistance of the cladding layers is attributed to their unique microstructure characteristics and the tribological behaviors of the phase constituents. The microstructure distribution can explain our results. By analyzing the image in Fig. 4, the volume fractions of the FeMoSi phase for different Si contents obtained to be 50.2, 58.6, and 70.5. The lower volume fraction of the reinforced FeMoSi dendrites is approximately $50.2 \%$ and the morphology is presented in fine and narrow features. The sprawl, fine, and narrow dendrites show a slightly lower wear resistance compared to denser and cell dendrites. It is imperative that $\mathrm{Si}$ enhanced stability of FeMoSi phase as a result of which the volume fraction of primary dendrites is raised. The increased volume fraction of the FeMoSi phase is the most important factor of strengthening. This result can be explained on the basis of the FeMoSi phase-attributed incorporation of atoms into a FeMoSi phase having a strong bonding element such as $\mathrm{Si}$. On the other hand, the FeMoSi phase has a complex hexagonal crystalline structure. The results suggest that a high Si content is effective in increasing the volume fraction of the FeMoSi phase and the wear resistance.

According to a study reported by Richardson, ${ }^{27,28)}$ abrasives with a hardness equal to or less than that of the worn surface are "soft abrasives", whereas abrasives harder than the worn surface are "hard abrasives". In this study, the hardness of quartz sand used in the test is around $900 \mathrm{HV}$. Consequently, the sand serves as a hard abrasive for the interdendrites and as a soft abrasive for the dendrites in the cladding layers. Thus, it is anticipated that the wear in the cladding layers will be predominantly controlled through the dendrite phases.

Figure 8 shows an SEM image of the worn surface of the multicomponent alloy cladding for various $\mathrm{Si}$ contents after the wear test. In the Si-free cladding layer, the worn surface shows a vestige of the microcutting and microplowing reaction. In contrast, the worn surface of the Si-added claddings (see Figs. 8(a)-8(c)) is relatively smooth with shallow grooves parallel to the sand movement. This feature is similar to a polished and etched metallograph on which the FeMoSi primary dendrites can be clearly identified. The worn surfaces, indicating the removal of materials, are associated 

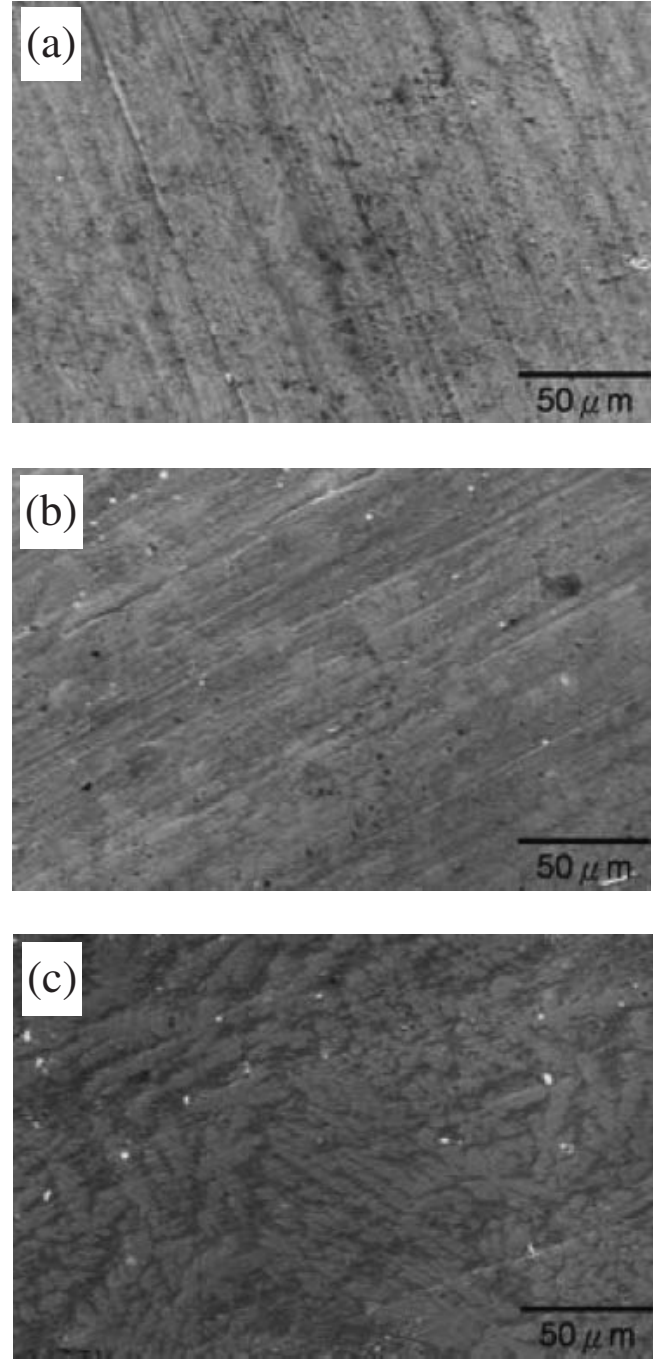

Fig. 8 Worn surface of GTAW cladding layers under dry sand rubber wheel wear test (a) 5.92 at\% Si (b) 10.72 at\% Si (c) 14.53 at $\% \mathrm{Si}$.

primarily with a microcutting mechanism in the interdendrite regions. The improved wear resistance of the claddings is principally due to an increase in the volume fraction of the dendrite phase that enhances the hardness and reduces the microcutting function. The primary dendrites of the multicomponent FeMoSi phase play an important role in resisting abrasive wear since they contain $\mathrm{Si}$, which has covalentdominant strong bonds that prevents the plastic deformation caused by microcutting. ${ }^{29-33)}$

\section{Conclusion}

According to this study, multicomponent alloy claddings with different $\mathrm{Si}$ contents were successfully deposited on low-carbon steel by a GTAW process. The primary dendritic and interdendritic phases are FeMoSi and BCC, respectively, and both phases contain multiple elements. The interdendrite morphologies in claddings with $\mathrm{Si}$ contents of 5.92 and 10.72 at $\%$ showed a net-like structure caused by spinodal decomposition, while those for claddings with Si contents of 14.53 at $\%$ had the form of nanoscale needle-like precipitates. The hardness of cladding layers was around $885 \mathrm{Hv}$. The wear resistance was improved by increasing the Si content.
The increase in the wear resistance was mainly caused by the increase in the FeMoSi dendritic volume fraction. The FeMoSi dendrites had covalent-dominant strong bonds, which enhanced their hardness and wear resistance.

\section{Acknowledgements}

This project was supported by the National Science Council of Taiwan under grant no. NSC-96-2221-E-005054 and the authors thank the MingDao University for providing FESEM analyses.

\section{REFERENCES}

1) Q. F. Peng: Wear 129 (1989) 195-203.

2) R. L. Deuis, J. M. Yellup and C. Subramanian: Compos. Sci. Technol. 58 (1998) 299-309.

3) J. K. Chen, P. Aaron and F. A. Allahdadi: Compos. Sci. Technol. 54 (1995) 35-44.

4) J. D. Damborenea: Surf. Coat. Tech. 100 (1998) 377-382.

5) M. Nakamichi, T. Takabatake and H. Kawamura: Fusion Eng. Des. 41 (1998) 143-147.

6) M. Eroglu and N. Ozdemir: Surf. Coat. Tech. 154 (2002) 209-217.

7) A. Ureña, M. D. Escalera and L. Gil: Compos. Sci. Technol. 60 (2000) 613-622.

8) G. Xu, M. Kutsuna, Z. Liu and K. Yamada: Surf. Coat. Tech. 201 (2006) 1138-1144

9) S. Buytoz and M. Ulutan: Surf. Coat. Tech. 200 (2006) 3698-3704.

10) T. Hejwowski: Vacuum 80 (2006) 1326-1330.

11) K. Gurumoorthy, M. Kamaraj, K. P. Rao and A. S. Rao, Venugopal: Mat. Sci. Eng. A 456 (2007) 11-19.

12) J. W. Yoo, S. H. Lee, C. S. Yoon and S. J. Kim: J. Nucl. Mater. 352 (2006) 90-96.

13) B. Cantor, T. H. Chang, P. Knight and A. J. B. Vincent: Mat. Sci. Eng. A 375 (2004) 213-218.

14) J. W. Yeh, S. K. Chen, S. J. Lin and J. Y. Gan: Adv. Eng. Mater. 6 (2004) 299-303.

15) P. K. Huang, J. W. Yeh, T. T. Shen and S. K. Chen: Adv. Eng. Mater. 6 (2004) 74-78.

16) T. K. Chen, T. T. Shun, J. W. Yeh and M. S. Wong: Surf. Coat. Tech. 188-189 (2004) 193-200.

17) M. R. Chen, S. J. Lin, J. W. Yeh, S. K. Chen, Y. S. Huang and C. P. Tu: Mater. Trans. 47 (2006) 1395-1401.

18) Y. Y. Chen, T. Duval, U. D. Hung, J. W. Yeh and H. C. Shih: Corros. Sci. 47 (2005) 2257-2279.

19) X. F. Wang, Y. Zang, Y. Qiao and G. L. Chen: Intermetallics 15 (2007) 357-362.

20) J. H. Chen, P. H. Hsing, P. N. Chen, M. C. Chen, C. M. Chang and W. Wu: Mater. Lett. (2008) 2490-2492.

21) A. L. Greer: Nature 366 (1993) 303.

22) R. E. Reed-Hill and R. Abbaschian: Physical Metallurgy Principles, (3rd ed., PWS, Boston, 1994).

23) U. S. Hsu, U. D. Hung, J. W. Yeh, S. K. Chen, Y. S. Huang and C. C. Yang: Mater. Sci. Eng. A 460 (2007) 403-408.

24) M. R. Chen, S. J. Lin, J. W. Yeh, S. K. Chen, Y. S. Huang and M. C. Chung: Metall. Mater. Trans. A 37A (2006) 1363-1369.

25) C. C. Tung, J. W. Yeh, T. T. Shun, S. K. Chen, Y. S. Huang and H. C. Chen: Mater. Lett. 61 (2007) 1-5.

26) W. A. Soffa and D. E. Laughlin: Proc. Inc. Conf: Solid-Solid Phase Transformation, (Pittsburgh, 1981).

27) R. Richardson: Wear 10 (1967) 291-309.

28) R. Richardson: Wear 14 (1969) 290-291.

29) Y. L. Fang, H. B. Tang and H. M. Wang: Intermetallics 14 (2006) $750-758$.

30) G. Sauthoff: Intermetallics 8 (2000) 1101-1109.

31) J. W. Newkirk and J. A. Hawk: Wear 251 (2001) 1361-1371.

32) G. Dune and H. M. Wang: Scr. Mater. 46 (2002) 107-111.

33) H. M. Wang, D. Y. Luan and L. Y. Zhang: Scr. Mater. 48 (2003) 1079-1184. 